\title{
ИМИТАЦИОННАЯ МОДЕЛЬ ОЦЕНКИ ВЛИЯНИЯ НЕМАТЕРИАЛЬНЫХ РЕСУРСОВ НА ПРОИЗВОДИТЕЛЬНОСТЬ ТРУДА ${ }^{1}$
}

\section{A SIMULATION MODEL FOR ASSESSING THE IMPACT OF INTANGIBLE RESOURCES ON LABOR PRODUCTIVITY}

\section{Ismagilova \\ E. Arylbaeva}

Summary. The expediency of using simulation models for solving the task of quantitative evaluation of intangible resources influence on the results of enterprise activity is substantiated. The possibilities and advantages of simulation modeling for solving this type of problems are revealed; the algorithm of model building is presented. Using econometric equations, a simulation model of assessing the impact of intangible resources (IMR) on the economic results of the business was developed. Factors reflecting human, organizational and information capitals were used as exogenous variables. The results of model approbation were analyzed, recommendations on the choice of managerial impacts contributing to the growth of labor productivity (LP) were formed.

Keywords: simulation model, labor productivity, intangible resources, production functions, economic performance of business.

\section{Исмагилова Лариса Алексеевна}

Д.т.н., профессор, г.н.С., Институт социальноэкономических исследований - обособленное структурное подразделение ФГБНУ УФИЦ РАН, г. Уфа ismagilova_ugatu@mail.ru

Арылбаева Эльвира Дамировна

Аспирант, Институт социально-экономических исследований - обособленное структурное подразделение ФГБНУУФИЦ РАН, г. Уфа elvira_arylbaeva@mail.ru

Аннотация. Обоснована целесообразность применения имитационных моделей для решения задачи количественной оценки влияния нематериальных ресурсов на результаты деятельности предприятия. Раскрыты возможности и преимущества имитационного моделирования для решения такого класса задач, представлен алгоритм построения модели. С применением эконометрических уравнений разработана имитационная модель оценки влияния нематериальных ресурсов (HMP) на экономические результаты бизнеса. В качестве экзогенных переменных использованы факторы, отражающие человеческий, организационный и информационный капиталы. Проанализированы результаты апробация модели, сформированы рекомендации по выбору управленческих воздействий, способствующих росту производительности труда (ПТ).

Ключевые слова: имитационная модель, производительность труда, нематериальные ресурсы, производственные функции, экономическая результативность бизнеса.

онным поведением в настоящее время является весьма актуальной.

Управление трудовыми ресурсами предприятия включает в себя целый комплекс задач, таких как планирование потребности в квалифицированных кадрах, поиск и набор персонала, его адаптация, обучение и переобучение, организация условий труда, медицинского обслуживания работников предприятия, формирование системы материального и морального стимулирования инновационного поведения персонала и т.д. [10]. Реализация процессов управления сопровождается весьма значительными затратами. Количественная 


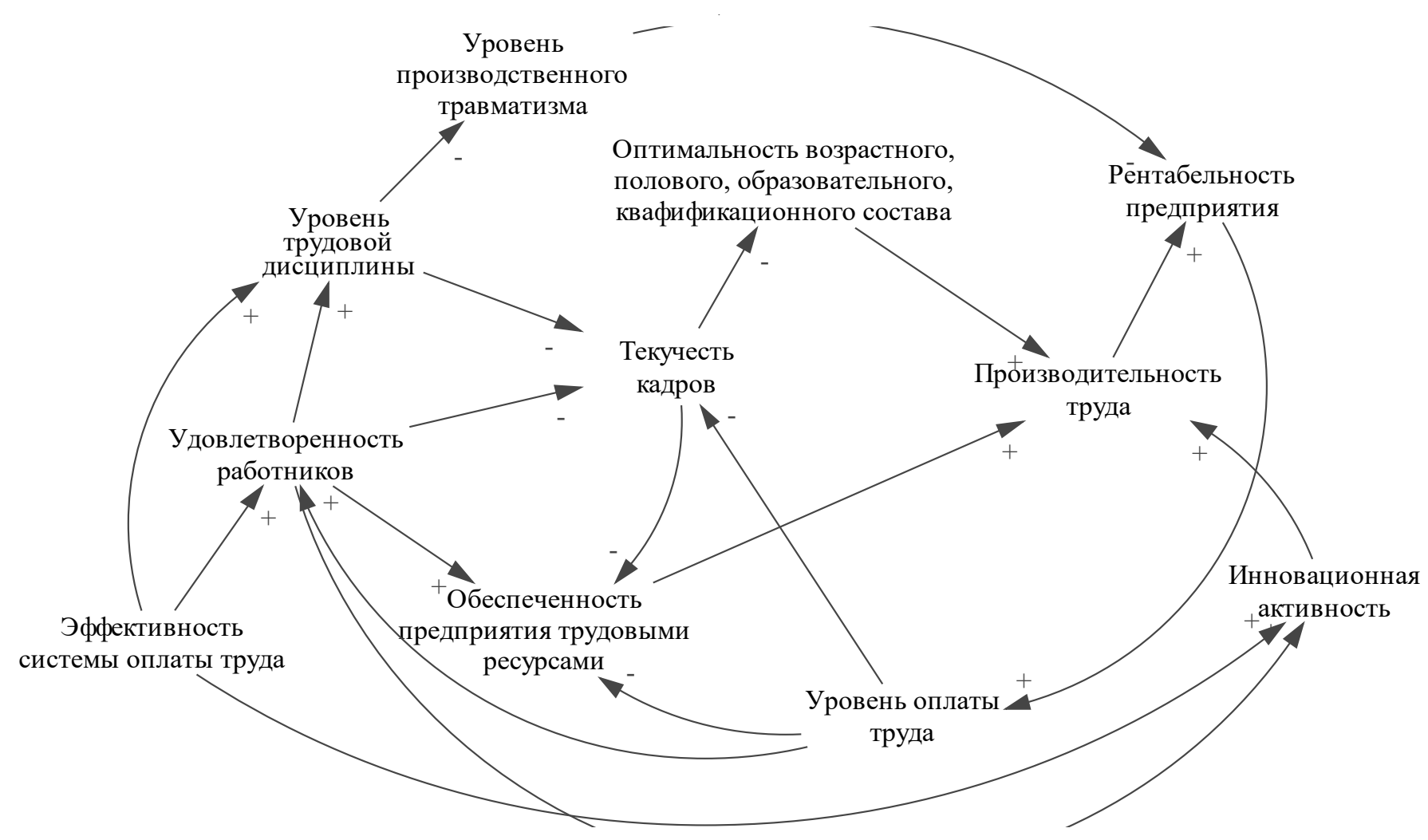

Рис. 1. Когнитивная карта проблемы управления трудовыми ресурсами

оценка эффективности вложений в развитие трудовых ресурсов сложная и плохоформализуемая задача. Оценка затрат на мероприятия по развитию персонала трудно сопоставима с экономическими результатами бизнеса, поскольку формируется в синергии со многими показателями.

Правильное и эффективное распределение средств по направлениям кадровой политики - задача актуальная для предприятий, особенно, высокотехнологичного сектора экономики.

Известно, что главной целью управления трудовыми ресурсами является стабильное обеспечение предприятия квалифицированным персоналом с такими качественными и количественными характеристиками, которые необходимы для достижения предприятием своих целей, при минимизации затрат на персонал. Поэтому любое управленческое решение в сфере управления персоналом должно обосновываться с позиций соотношения затрат и результатов [3].

Персонал предприятия как объект управления оценивается большим числом показателей, характеризующих различные аспекты состояния трудовых ресурсов, такие как обеспеченность трудовыми ресурсами; текучесть кадров; структура возрастного, гендерного, обра- зовательного, квалификационного состава персонала; производительность труда и ее влияние на показатели рентабельности предприятия; уровень оплаты труда работников предприятия; уровень производственного травматизма; уровень трудовой дисциплины; уровень удовлетворенности работников предприятия; их инновационная активность и т.п. Важно отметить, что перечисленные аспекты являются в значительной степени взаимосвязанными, взаимовлияющими друг на друга. Все перечисленное многообразие факторов группируется и теоретически переосмысляется в концепции нематериальные ресурсы предприятия (HMP). В данной статье авторы придерживаются обоснованной ранее в работе [4], структуры НМР как взаимодействия организационного, информационного и человеческого капиталов.

Учитывая синергетический характер влияния факторов и их противонаправленное действие, разработка формальной математической модели оценки влияния HMP на производительность труда возможна, но достаточно трудоемка и главное не ориентирована на экспериментальное исследование быстро меняющихся ситуаций реального управления предприятием. Когнитивное моделирование как одно из направлений искусственного интеллекта, сочетает в своих методах структурно-формальные и экспертные оценки. Описа- 
Стратегические цели предптицтия

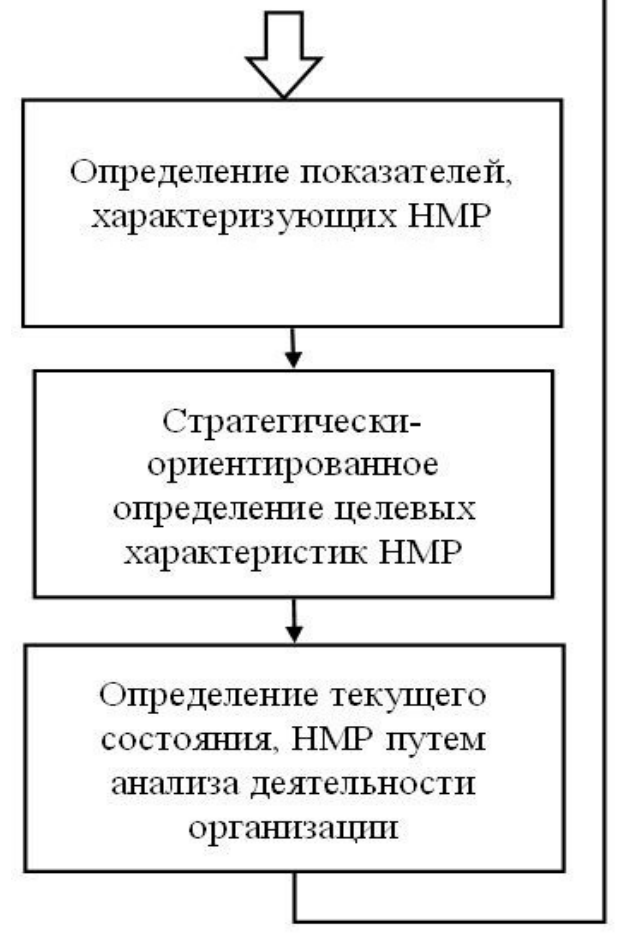

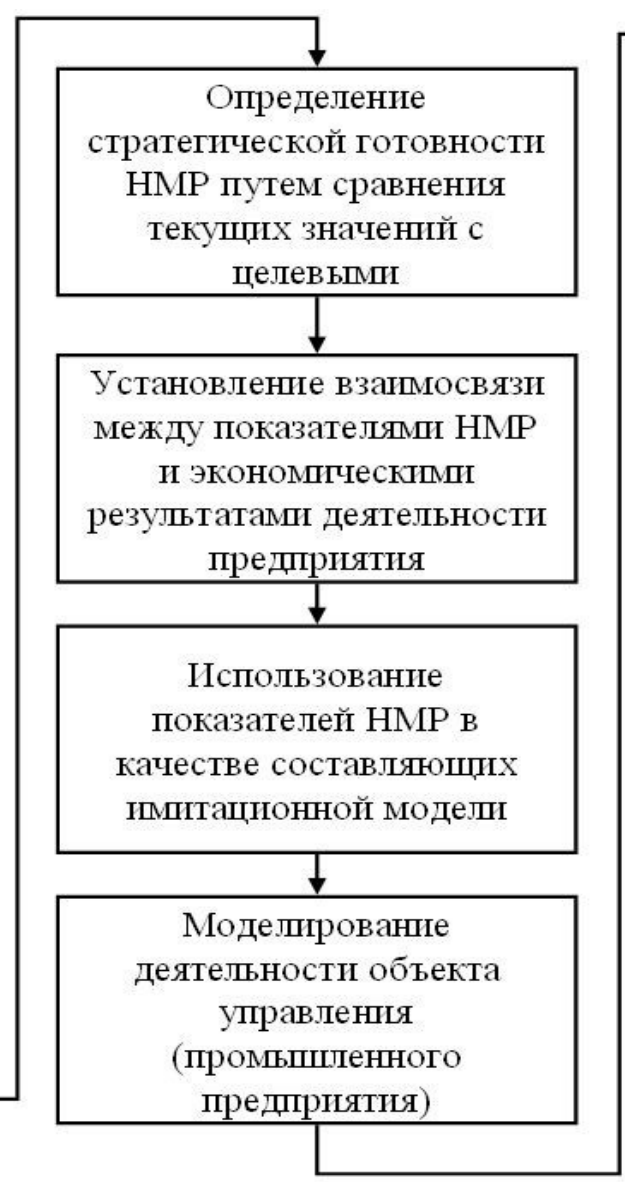

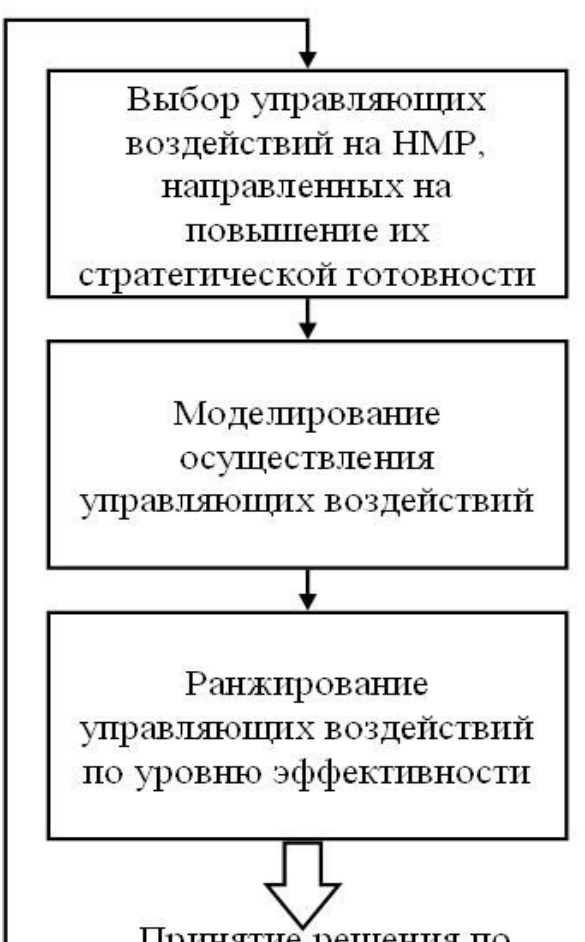

Принятие решения по осуществленпю напболее эффективных управленческих воздействй

Рис. 2. Алгоритм построения имитационной модели

ние и исследование взаимодействия множества факторов предметной области, возможно при построении когнитивных карт $[1,2]$.

Когнитивная карта проблемы управления трудовыми ресурсами предприятия, позволяющая описать взаимосвязи между перечисленными аспектами, приведена на рисунке 1.

Когнитивная карта обосновывает содержание имитационной модели как экономико-математического представления численного изучения системы. Имитационная модель предназначена для использования в процессе компьютерного моделирования для проведения расчетных экспериментов [4]. Эксперимент над такой моделью состоит в многовариантном подборе значений экзогенных (вводимых) переменных с целью получения на выходе наилучших из возможных результатов расчетов эндогенных величин. Здесь речь идет об оценке взаимосвязи роста производительности труда и изменения экономических результатов бизнеса [6]. Проверяется аксиома, что рост производительности труда всегда благо для бизнеса.
Предлагается использовать класс дискретно-событийных моделей как наиболее распространенный метод для построения имитационных моделей экономических процессов, когда в процессе моделирования состояние переменных меняется условно мгновенно в конкретные периоды времени. Одним из программных продуктов дискретно-событийного моделирования является среда имитационного моделирования PowerSimStudio [7]. По сравнению с другими средствами динамического имитационного моделирования (iThink, iDecide, Simulink), система PowerSimStudio обладает рядом преимуществ, позволяющих проводить машинные эксперименты при решении задач, в том числе и оптимизационных [7].

В имитационной модели устанавливается взаимосвязь между экономическими показателями деятельности предприятия (или в общем случае любого бизнеса), операционными показателями и характеристиками нематериальных ресурсов. Базовые характеристики бизнес-процессов предприятия, такие как выручка, издержки и прибыль формируются под влиянием блоков: управления трудом, анализа рынка и формирования ин- 
теллектуального капитала предприятия только за счет развития компетенций работников. Организационный капитал характеризуется в модели количеством заказов и объемом выпуска продукции. Информационный капитал, как элемент воздействия на производительность труда, в данной модели учитывается опосредованно. Взаимосвязь между показателями устанавливается с помощью задания параметров «конверторов», «коннекторов» и «потоков». Цель имитационного моделирования достижение наилучших значений показателя «прибыль» в условиях ограниченности потока заказов и количества используемых материальных ресурсов [8].

Для построения имитационной модели оценки эффективности влияния НМР на производительность труда предлагается алгоритм, описывающий последовательность выполнения действий по определению показателей, характеризующих НMР, установлению взаимосвязей между показателями Пт и экономическими результатами деятельности организации, выбору и обоснованию управленческих воздействий в зоне трудовых функций. Схема алгоритма представлена на рисунке 2.

В качестве управленческих воздействий на производительность труда через НMР, анализируемых в рамках имитационной модели, используются воздействия, необходимые для повышения стратегических готовностей ПТ до целевых уровней, среди которых могут быть выделены:

- повышение уровня компетентности персонала через обучение;

- приобретение необходимого программного и аппаратного обеспечения;

- мероприятия по улучшению управленческих практик на предприятии.

В качестве примера апробирования предложенного подхода к управлению производительностью труда через наращивание уровня нематериальных ресурсов и формирование синергетических эффектов их взаимодействия в статье рассматривается строительное предприятие реального сектора экономики, на котором трудятся работники с разным уровнем производственных и управленческих компетенций.

Для построения квалиметрических оценок степени значимости факторов и выявления их синергетического эффекта при моделировании необходимо разработать эконометрическую зависимость, отражающую сущностные отношения между результатом труда и факторами производства. Теоретической основой такого уравнения может служить производственная функция Кобба-Дугласа [9]. Функция Кобба-Дугласа чаще всего используется для описания среднемасштабных хозяй- ственных объектов, характеризующихся устойчивым, стабильным функционированием (вовлечение новой единицы ресурса приносит эффект, пропорциональный средней производительности имеющегося ресурса). Производственная функция данного вида может быть использована в целях анализа работы крупных и средних предприятий, с численностью работников от 100 человек и более [4,9].

Общий вид используемой неоклассической производственной функции представлен формулой (1).

$$
Y=A \prod_{i=1}^{n} X_{i}^{\gamma_{i}}
$$

где, $Y$ - объем выпуска продукции;

$A$ - совокупная производительность факторов производства, характеризующая технологический и организационный уровень производства;

$X_{i}$ - факторы производства, существенные для анализа выпуска продукции и значимые для управления;

$\gamma_{i}$ - коэффициенты, характеризующие эластичность объема выпуска по факторам производства.

Таким образом, проблема управления нематериальными ресурсами состоит в выявлении количественных закономерностей влияния НМР на экономические результаты деятельности предприятия. При этом функция (1) может быть использована в практических целях для оценки степени влияния изменений нематериальных ресурсов на экономические результаты деятельности конкретных предприятий $[4,5,9]$.

Преобразование и линеаризация в частных производных производственной функции с некоторыми дополнительными ограничениями подробнее описана в работе [4] и используется в данной статье для получения некоторых оценок значимости или восприимчивости управленческих решений при моделировании.

Схема имитационной модели деятельности ООО «Стройавтомаш» представлена на рисунке 3.

Основными структурными элементами, которые показаны на рисунке 3, и используются в имитационной модели Power Sim Studio являются:

- «коннекторы» (отображаются стрелками), с помощью которых данные передаются между структурными блоками.

- «конверторы» (отображаются кружочками), задачей которых является преобразование ресурсных потоков. «Конверторы» используются в качестве переменных;

- «константы» (отображаются ромбиками), они используются в целях задания значений заранее определенных входных данных; 
File Edit View Format Diagram Layout Simulation Window Help

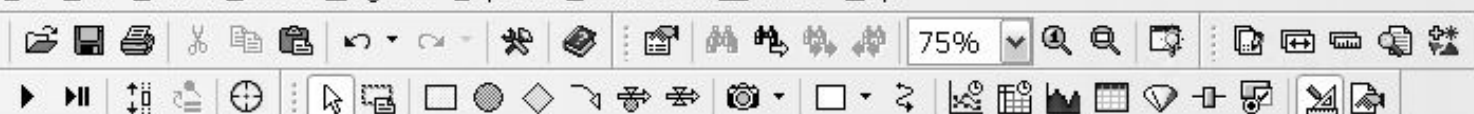

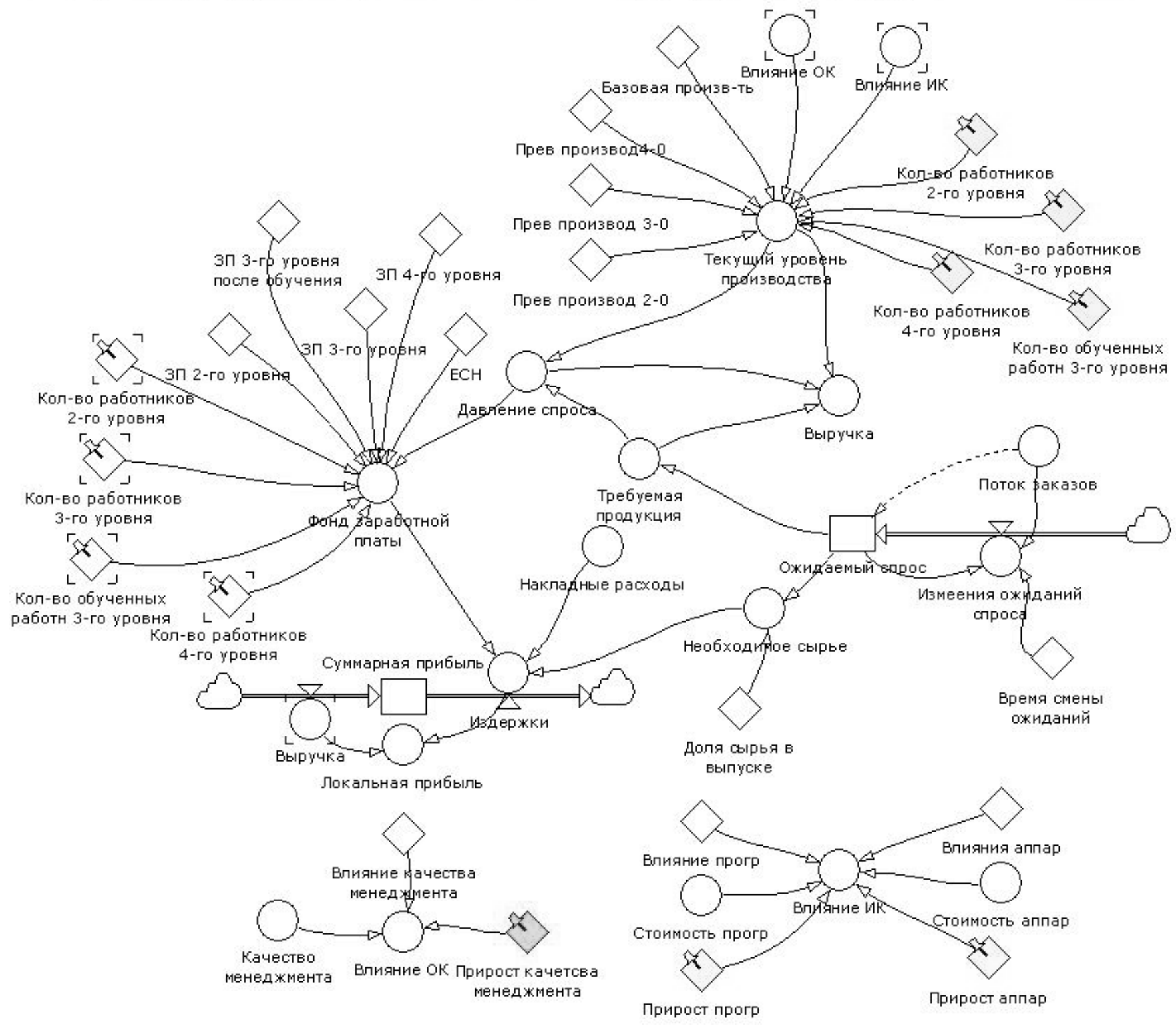

Рис. 3. Схема имитационной модели деятельности ООО «Стройавтомаш»

- «потоки» (отображаются стилизованными стрелками с кружочками-конверторами), это каналы, использующиеся для описания передачи ресурсных потоков между блоками. Вход и выход из блока является «потоком». В «потоке» ресурсный потенциал также может претерпевать требуемые преобразования.

- «накопители» (отображаются прямоугольниками), смысл которых заключаются в том, что отображаются ресурсы (материал, финансовые ресурсы, сырье, компоненты, заявки, заказы) по- ступающие из «потока». Сроки и количество хранимых ресурсов определяется режимами входа и выхода [4].

Переменная «Человеческий капитал» в данной модели условно представлена как совокупность работников второго, третьего и четвертого уровней компетентности. В конкретном примере на предприятии выделено 5 работников, обладающих 3-м уровнем компетентности (ИТР), 2 работника, обладающих 4-м уровнем компетентности (учредители) и 20 работников, обладающих 
Таблица 1. Результативность управленческих воздействий

\begin{tabular}{|l|l|l|l|}
\hline Управленческое воздействие & $\begin{array}{l}\text { Стоимость } \\
\text { воздействия, руб. }\end{array}$ & $\begin{array}{l}\text { Прирост производственной } \\
\text { мощности,\% }\end{array}$ & $\begin{array}{l}\text { Стоимость по процентам } \\
\text { прироста, руб. }\end{array}$ \\
\hline Обучение ИТР & 19700 & 5,27 & 3737 \\
\hline Приобретение системы СРМ & 30000 & 6,27 & 4782 \\
\hline Повышение качества менеджмента & 480000 & 1,57 & 305732 \\
\hline Итого & 529700 & 13,11 & 104750 \\
\hline
\end{tabular}

2-м уровнем компетентности (производственные рабочие). Вопросы оценки компетенций не так сложны и относятся к экспертной сфере. Количество уровней компетенций и доля работников при моделировании могут меняться в зависимости от целей обучения и особенностей производства.

Переменная «Текущий уровень производства», отражающая производственную мощность предприятия, представлена зависящей от численности работников каждого из уровней компетентности и от уровней производительности $\varphi_{2}, \varphi_{3}, \varphi_{4}$, соотношения которых были получены, на основе эконометрической модели следующего вида:

$$
\begin{aligned}
& \ln Y=\ln A+\gamma_{M} \ln M+\gamma_{K} \ln K+ \\
& +\gamma_{L}\left[\ln L+S_{2} \cdot \varphi_{2}+S_{3} \cdot \varphi_{3}+S_{4} \cdot \varphi_{4}\right] .
\end{aligned}
$$

При этом влияние информационного и организационного капиталов на производственную мощность отражено в качестве экзогенных переменных «Влияние ИР» и «Влияние ОР» воздействующих на общее значение текущего уровня производства с заранее оцененными интенсивностями и определенными по эконометрическим уравнениям аналогичной структуры.

В рамках модели описывается деятельность предприятия при стабильном потоке заказов. Изменение потока заказов оказывает влияние на ожидаемый учредителями спрос с задержкой в один месяц. Переменная «Требуемая продукция» характеризует плановый (или фактический для обратной задачи) в объем производства и равна величине потока «Ожидаемый спрос».

Издержки предприятия определяются затратами на сырье, накладными расходами и фондом заработной платы. Переменная «Необходимое сырье» зависит от ожидаемого спроса и доли сырья в готовом продукте. Для анализируемого предприятия она принята равной 45\%. Переменная «Накладные расходы» определяет долю постоянных затрат ООО «Стройавтомаш» и равна 234 тыс. рублей в месяц. Переменная «Фонд заработной платы» зависит от распределения работников по уровням компетентности и значений среднемесячной заработной платы, соответствующих каждому из уровней компетентности, используется повременная форма оплаты труда для всех работников. Если форма оплаты труда будет меняться, то в модели возможна настройка с помощью весовых коэффициентов. Это и преимущество, и недостаток имитационных моделей как класса экономико-математических моделей.

Согласно результатам операционной деятельности ООО «Стройавтомаш» в предыдущих периодах, среднемесячное значение выработки составило около Змлн. рублей в месяц.

Текущий штат предприятия сформирован на основе среднемесячного значения спроса и результатов оценки значимости факторов по эконометрической модели (формула 2), делается предположение, что на анализируемом предприятии относительное соотношение производительности работника 2-го, 3-го и 4-го уровней компетентности над производительностью работника базового уровня компетентности составляет 56,3\%, $90,8 \%$ и 138,5\% соответственно. Значения констант имитационной модели: «Прев производ 2-0», «Прев производ 3-0» и «Прев производ 4-0» заданы в относительных единицах. Тогда значение среднемесячной выработки работника базового уровня компетентности может быть вычислено как отношение спроса и суммарной доли работников по уровням компетенций и значениям интенсивностей.

Таким образом, среднемесячная производственная мощность предприятия без учета сверхурочных часов, выражаемая переменной «Текущий уровень производства», позволяет оценить влияние изменения структуры рабочей силы на экономические результаты деятельности предприятия.

Предложенный подход к построению эконометрической модели оценки влияния информационного и организационного капиталов на основе данных об уровне вложений средств в эти сферы, позволяет моделировать и количественно оценивать эффективную структуры затрат на развитие предприятия.

В процессе симуляции решаются прямая и обратная задачи. Можно оценить эффективность инвести- 
ций или определить сколько потребуется средств для достижения целевого уровня экономических результатов. При этом строится прогноз чистой прибыли предприятия за текущий год в зависимости от изменения характеристик нематериальных ресурсов по их видам направлениям деятельности. Прогнозируемая величина совокупной чистой прибыли за год, при сохранении всех параметров предприятия на исходном уровне (до осуществления каких-либо управленческих воздействий по повышению стратегической готовности НМР) составила при моделировании 2545200 руб.

Была осуществлена имитация работы предприятия при следующих управленческих воздействиях с учетом предполагаемых затрат:

- обучение всех ИТР до 4-го уровня компетентности;

- внедрение системы CPI;

- улучшения качества управленческих практик на предприятии.

Повышение уровня компетентности работников, согласно заданным условиям моделирования, приводит к росту на $12 \%$ их заработной платы. В результате описанных управленческих воздействий наблюдается рост значения переменной «Текущий объем производства» на $13,11 \%$. В тоже время, значение прогнозируемой совокупной чистой прибыли снижается до 2325 600p., вследствие повышения заработной платы обученных работников.

Для исправления ситуации имеется две возможности: сократить часть персонала или повысить поток заказов на 393359 руб./мес. В целях поддержания лояльности персонала предпочтительно осуществить привлечениедополнительныхзаказов. В случае привлечения дополнительных заказов на сумму 393400 руб./ мес. прогнозируемое значение совокупной чистой прибыли составит 3977699 руб., что на 56,28\% выше первоначального уровня. В абсолютном выражении прирост прибыли составит 1432499 руб., что в 2,7 раза покрывает необходимые для осуществления управленческих воздействий затраты.

Стоимость каждого из управленческих воздействий и его вклад в прирост производственной мощности представлены в таблице 1. Согласно данной величине наиболее предпочтительным является обучение ИТР, далее следует приобретение системы СРМ. Повышение качества управленческих практик при этом является самым дорогим и генерирует наименьший прирост производственной мощности, что делает управленческой воздействие по повышению стратегической готовности организационного ресурса наименее предпочтительным в случае ограниченности доступных для инвестирования финансовых ресурсов.

Предложенный подход к решению проблемы количественной оценки степени влияния нематериальных ресурсов на производительность труда путем имитационного моделирования позволяет решать актуальные для стратегического управления предприятием задачи инвестирования и управления ресурсами. Нематериальные ресурсы играют существенную роль в повышении экономической результативности бизнеса, но требуют значительных инвестиций, поэтому оценка эффективности инвестирования в человеческий, информационный и организационный капитал анализируемого предприятия, ранжирование управленческих воздействий на производительность труда являются актуальной задачей, разрешимой с помощью когнитивного анализа имитационного моделирования.

Приведенный в статье конкретный пример разработки модели свидетельствует о работоспособности предложенного подхода.

\section{ЛИТЕРАТУРА}

1. Арылбаева Э.Д., Исмагилова Л.А. Когнитивное моделирование как инструмент стратегического менеджмента // Управление. Экономический анализ. Финансы. Сборник научных трудов. Уфа, 2019. С. 8-15.

2. Гилева Т.А., Галимова М.П., Калмыкова С.В. Разработка программы развития человеческих ресурсов предприятия на основе когнитивного моделирования // Известия Юго-Западного государственного университета. 2017. Т. 21, № 2(71). С. 110-121.

3. Загребельная Н.С., Бостоганашвили Е.Р. Управление человеческими ресурсами в цифровой экономике // Экономика: вчера, сегодня, завтра. 2019. Т. 9, № 1-1. С. 374-384.

4. Исмагилова Л.А., Радыгин Ю.А. Эконометрический подход к оценке эффективности управления нематериальными ресурсами // Вестник экономической интеграции. 2009. № 4. С. 69-75.

5. Ларина Т.Е. Оценка экономической эффективности использования нематериальных активов // Гуманитарные, социально-экономические и общественные науки. 2017. С. 161-163. URL: https://cyberleninka.ru/article/n/otsenka-ekonomicheskoy-effektivnosti-ispolzovaniya-nematerialnyh-aktivov/ viewer (дата обращения: 21.07.2021).

6. Половкина Э.А., Савдур С.Н. Взаимосвязь производительности труда и экономического роста // Вестник экономики, права и социологии. 2016. № 2. C. 94-96. URL: https://cyberleninka.ru/article/n/vzaimosvyaz-proizvoditelnosti-truda-i-ekonomicheskogo-rosta/viewer (дата обращения: 21.07.2021). 
7. Рамазанов Р.Р. Сравнительная характеристика подходов имитационного моделирования общественных процессов // Вестник УгНту. Наука, образование, экономика. Серия: Экономика. 2017. № 2 (20). С. 67-77. URL: https://cyberleninka.ru/article/n/sravnitelnaya-harakteristika-podhodovimitatsionnogo-modelirovaniya-obschestvennyh-protsessov/viewer (дата обращения: 21.07.2021).

8. Ткачев А.Н., Багдасарова М.В. Имитационное моделирование финансово-хозяйственной и производственной деятельности предприятий методами системной динамики // Современные проблемы науки и образования. 2014. № 5. URL: http://science-education.ru/ru/article/view?id=14800 (дата 06ращения: 21.07.2021).

9. Юсим В.Н., Филиппов В.С. Производственная функция Кобба - Дугласа и управление экономико-технологическим развитием // Вестник Российского экономического университета им. Г.В. Плеханова. 2018. № 2 (98). С. 105-114. URL: https://cyberleninka.ru/article/n/proizvodstvennaya-funktsiya-kobbaduglasa-i-upravlenie-ekonomiko-tehnologicheskim-razvitiem/viewer (дата обращения: 21.07.2021).

10. Mezentseva L.V., Kurkov K.N., Arsakhanova Z.A., Martynenko M.V., Takmakova E.V., Guseva T.G. Human resource management strategy: implementation features, prerequisites, and effective results // Espacios. 2018. Vol. 39 (№ 31). P. 31.

( ) Исмагилова Лариса Алексеевна ( ismagilova_ugatu@mail.ru ), Арылбаева Эльвира Дамировна ( elvira_arylbaeva@mail.ru ).

Журнал «Современная наука: актуальные проблемы теории и практики»

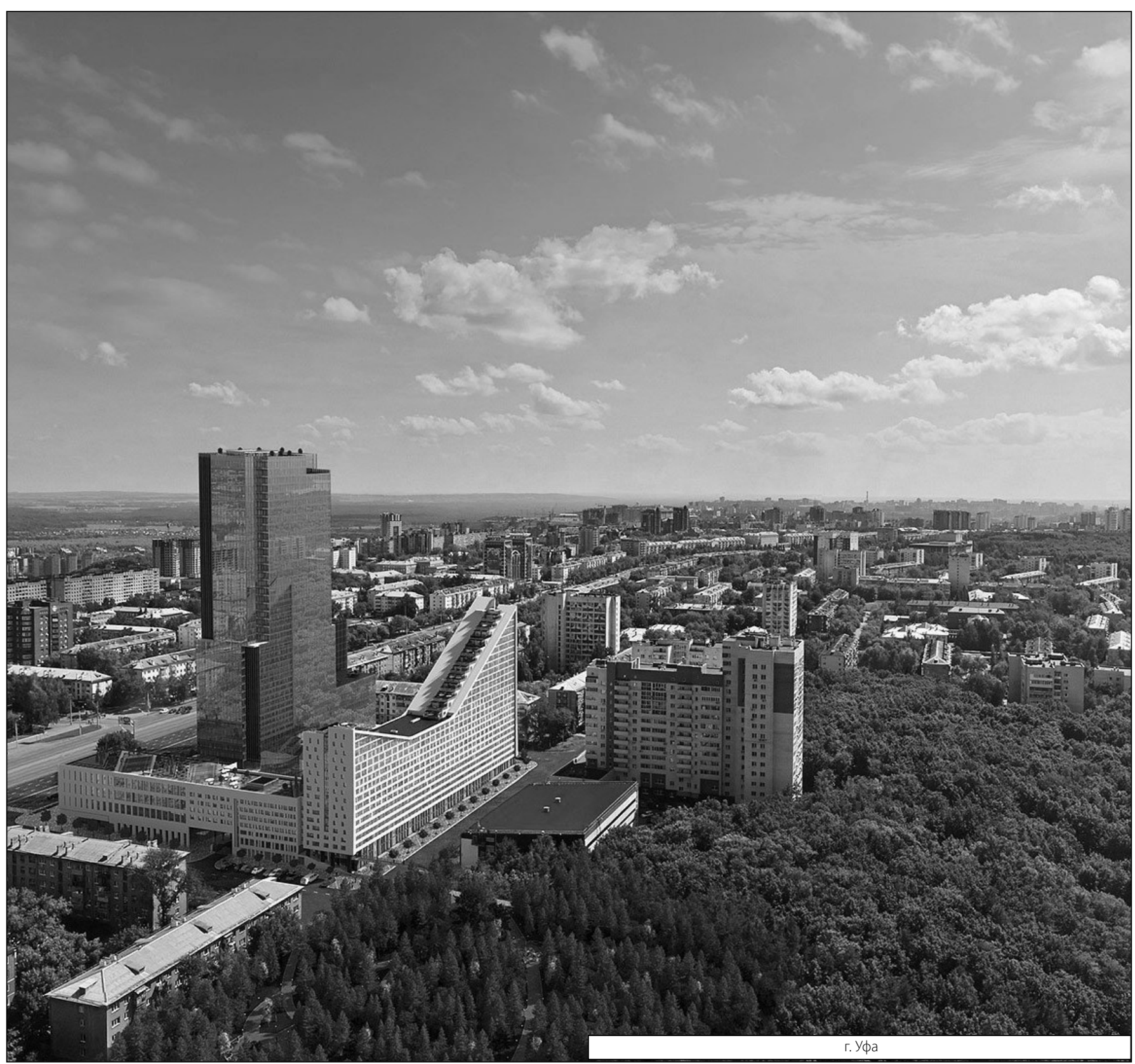

